\title{
Pancreatic abnormalities and AIDS related sclerosing cholangitis
}

Julian P Teare, Carmel A Daly, Catherine Rodgers, Simon P G Padley, Richard J Coker, Janice Main, John R W Harris, David Scullion, Gary P Bray, John A Summerfield

Objectives: Biliary tract abnormalities are well recognised in AIDS, most frequently related to opportunistic infection with Cryptosporidium, Microsporidium, and cytomegalovirus. We noted a high frequency of pancreatic abnormalities associated with biliary tract disease. To define these further we reviewed the clinical and radiological features in these patients.

Methods: Notes and radiographs were available from two centres for $83 \mathrm{HIV}$ positive patients who had undergone endoscopic retrograde cholangiopancreatography for the investigation of cholestatic liver function tests or abdominal pain.

Results: 56 patients had AIDS related sclerosing cholangitis (ARSC); 86\% of these patients had epigastric or right upper quadrant pain and $52 \%$ had hepatomegaly. Of the patients with ARSC, 10 had papillary stenosis alone, 11 had intra- and extrahepatic sclerosing cholangitis alone, and 35 had a combination of the two. Ampullary biopsies performed in 24 patients confirmed an opportunistic infection in 16. In 15 patients, intraluminal polyps were noted on the cholangiogram. Pancreatograms were available in 34 of the 45 patients with papillary stenosis, in which 29 $(81 \%)$ had associated pancreatic duct dilatation, often with associated features of chronic pancreatitis. In the remaining 27 patients, final diagnoses included drug induced liver disease, acalculous cholecystitis, gall bladder empyema, chronic B virus hepatitis, and alcoholic liver disease. Conclusion: Pancreatic abnormalities are commonly seen with ARSC and may be responsible for some of the pain not relieved by biliary sphincterotomy. The most frequent radiographic biliary abnormality is papillary stenosis combined with ductal sclerosis.

(Genitourin Med 1997;73:271-273)

Keywords: AIDS; cholangitis, sclerosing; pancreas, abnormalities

\section{Department of}

Gastroenterology, St Mary's Hospital, Paddington, London J P Teare

J A Summerfield

Department of Genitourinary Medicine, St Mary's Hospital, Paddington, London C Rodgers

R J Coker

J Main

J R W Harris

Department of

Radiology, St Mary's

Hospital, Paddington, London

D Scullion

Department of

Radiology, Chelsea

and Westminster

Hospital, Fulham

Road, London

C A Daly

S P G Padley

Department of

Gastroenterology,

Chelsea and

Westminster Hospital, Fulham Road, London G P Bray

Correspondence to: Dr J P Teare, Endoscopy Unit, Clarence Wing, St Mary's Hospital, Praed

Street, London W2 1NY.

Accepted for publication

3 March 1997

\section{Introduction}

Investigation of HIV infected patients with right upper quadrant pain and obstructive liver function tests led to the recognition of a syndrome termed AIDS related sclerosing cholangitis (ARSC).$^{12}$ Cello $^{1}$ classified biliary tract abnormalities in a series of 26 patients with AIDS into four distinct radiographic patterns:

(1) papillary stenosis alone, with a common bile duct greater than $8 \mathrm{~mm}$ in diameter and distal 2-4 mm tapering of the common bile duct,

(2) intrahepatic sclerosing cholangitis alone,

(3) sclerosing cholangitis in association with papillary stenosis,

(4) long extrahepatic bile duct strictures with or without intrahepatic sclerosing cholangitis.

The most common pattern was sclerosing cholangitis in association with papillary stenosis. ${ }^{1}$ The majority of these biliary abnormalities are associated with cytomegalovirus (CMV) and Cryptosporidium sp infection. ${ }^{3}$ All 26 patients in this early series ${ }^{1}$ were noted to have normal pancreatograms. Furthermore pancreatic abnormalities were not reported in a recent larger series of 45 patients. ${ }^{4}$

Pancreatic disease in human immunodeficiency virus (HIV) infection can be the result of opportunistic infection, neoplasia, drug toxicity or causes unrelated to AIDS such as alcohol abuse or gallstones. ${ }^{5}$ The spectrum of disease ranges from asymptomatic necropsy findings $^{6}$ to acute lethal pancreatitis. ${ }^{7}$
Opportunistic infection is most commonly caused by $\mathrm{CMV}^{7}$ with $13 \%$ of unselected necropsies having evidence of CMV pancreatic involvement. CMV may cause minimal pancreatic inflammation, ${ }^{8}$ or acute pancreatitis. ${ }^{9}$ In only one case has pancreatic infection been noted to be associated with hepatobiliary involvement and ARSC.

We noted the presence of pancreatic abnormalities at endoscopic retrograde cholangiopancreatography (ERCP) performed for the investigation of cholestatic liver function tests and right upper quadrant pain and therefore performed a retrospective analysis of 83 patients to document the prevalence of such changes.

\section{Patients and methods}

The study was based at two specialist referral centres providing care for HIV positive patients. The case records, laboratory results, radiological findings, and computerised records of patients presenting with obstructive liver function tests or abdominal pain who underwent ERCP between 1989 and July 1995 were analysed retrospectively. The radiographs were then reported blindly.

\section{Results}

ERCP was performed in a total of 83 patients with obstructive liver function tests, of which 56 were shown to have ARSC. Of the patients 
Figure 1 Papillary stenosis with dilated intraand extrahepatic bilary tree and mild intrahepatic duct irregularity (type III ARSC). Dilated irregular main pancreatic duct with ectatic side branches.

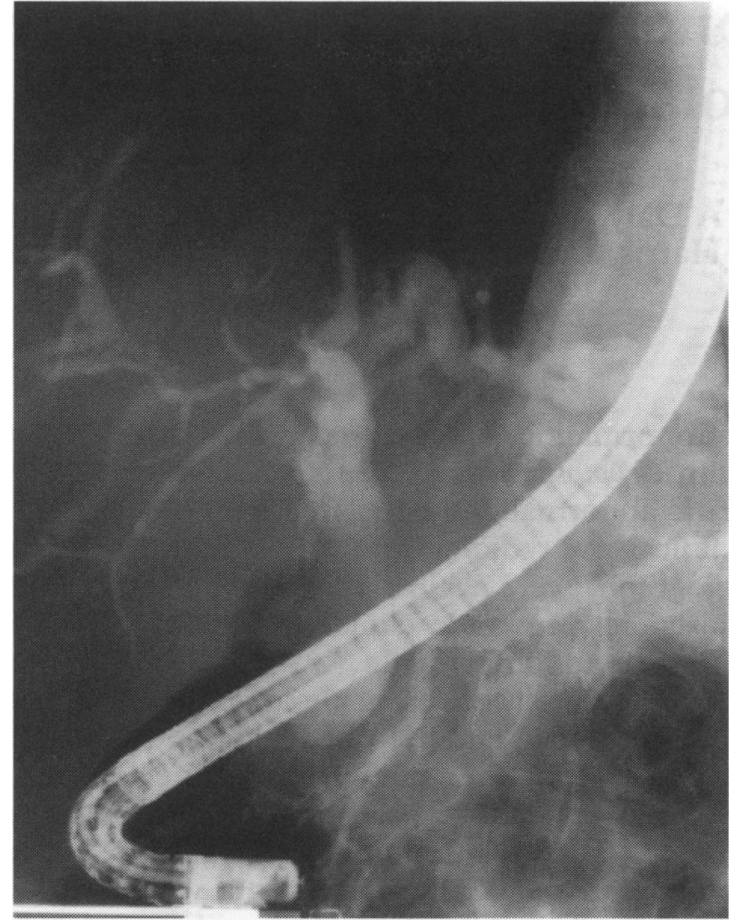

with ARSC, 48 (86\%) experienced epigastric or right upper quadrant pain, $37(66 \%)$ had diarrhoea, 30 (53\%) had weight loss of $>4 \mathrm{~kg}$, and 13 (24\%) had fever. Hepatomegaly, often tender, was seen in $29(52 \%)$. Three patients were asymptomatic.

\section{RADIOLOGICAL FINDINGS}

Ten patients had papillary stenosis alone (type I), 11 patients had intra- and extrahepatic sclerosing cholangitis alone (type II), and 35 had a combination of the two (type III). No patient had the fourth type ${ }^{10}$ with a long extrahepatic biliary stricture. In the 45 patients with a dilated common bile duct (types I and III), the main pancreatic duct was opacified in 34 patients and found to be dilated in 29 . The normal diameter was taken to be $4 \mathrm{~mm}$ in the head, $3 \mathrm{~mm}$ in the body, and $2 \mathrm{~mm}$ in the tail. In 18 the duct was enlarged greater than $6 \mathrm{~mm}$ in diameter associated with irregularities of the main duct and side branches similar to the changes seen in idiopathic or alcohol induced

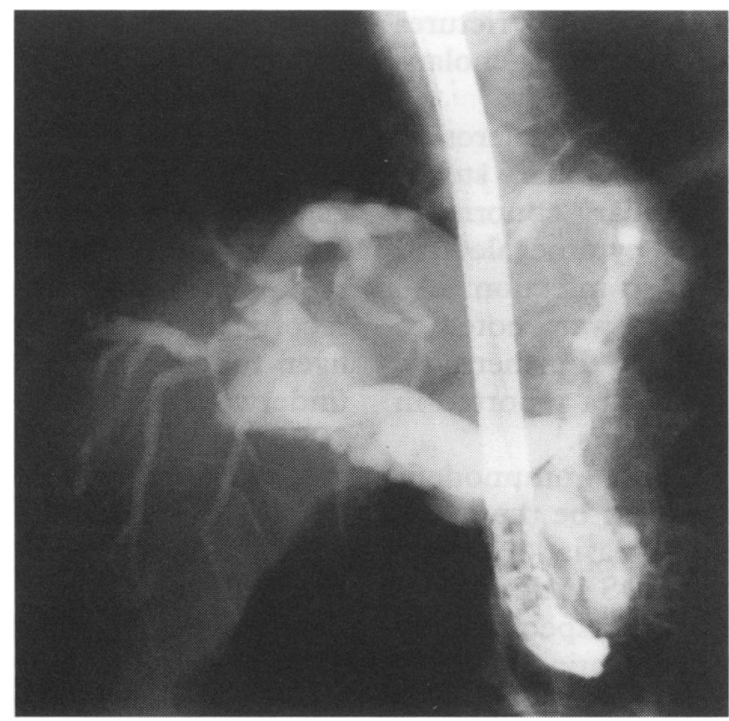

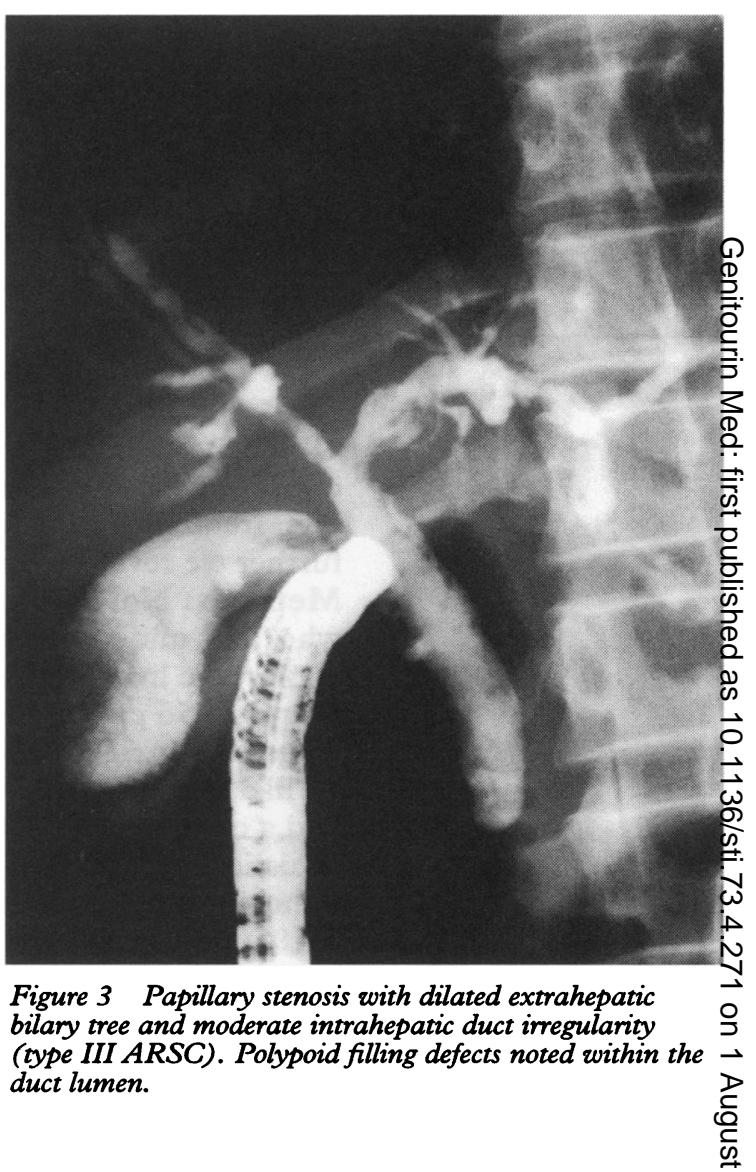

chronic pancreatitis (figs 1 and 2). There werece no clinical characteristics specific for this group. One of the patients with type I and 11 of the patients with type III ARSC had polypoids filling defects within the biliary tree (fig 3 ).

Ampullary or biliary biopsy was successfuh̆ in obtaining a microbiological diagnosis in $16^{\circ}$ of 24 patients where performed: CMV in six, $\overrightarrow{\overrightarrow{0}}$ Cryptosporidium in six, CMV and Cryptosporidium in one, and one each demonstrated Microsporidium, Mycobacterium avium intracellulare, or fungi. One patient had ampullary? non-Hodgkin's lymphoma. ${ }^{11}$ In this patient? the cholangiographic findings regressed on treatment of the lymphoma.

Mean survival for patients with ARSC waso 6-8 months (range 2 days to 24 months).

\section{BIOCHEMICAL FINDINGS}

There were no significant differences in bio- 0 chemical indices between any of the patiento subgroups (table).

In the 27 patients who did not have ARSC on cholangiography, it can be seen that the biochemical values differed little. Clinical symptoms and signs were also similar with abdominal pain present in 23 (85\%), diar-0 rhoea in $10(38 \%)$, weight loss in $12(45 \%) \stackrel{\mathbb{D}}{\Omega}$ hepatomegaly in $17(63 \%)$, and fever in seven $(28 \%)$. Final diagnoses in this group includedo hepatic non-Hodgkin's lymphoma (two), cholecystitis (one), acalculous cholecystitis (two), gall bladder empyema (one), ampullary Kaposi's sarcoma (one), drug induced liver? disease (two), chronic hepatitis $\mathbf{B}$ virus induced liver disease (three), choledocholithiasis (one), CMV colitis (one), and alcoholic liver disease. The final diagnosis or reason for the ERCP was unclear in the remainder. 
Biochemical findings in patients subgroups

\begin{tabular}{lcccc}
\hline & Type I & Type II & Type III & Non-ARSC \\
\hline n & 10 & 11 & 35 & 27 \\
ALT & $38(201)$ & $77(112)$ & $50(102)$ & $49(133)$ \\
& $24-1640$ & $35-298$ & $12-546$ & $10-900$ \\
AST & $39(344)$ & $83(102)$ & $47(73)$ & $37(88)$ \\
& $25-1560$ & $22-206$ & $14-535$ & $10-520$ \\
Alk P & $478(706)$ & $584(1017)$ & $565(909)$ & $376(681)$ \\
& $77-1590$ & $247-3953$ & $128-3730$ & $46-2449$ \\
Bilirubin & $6 \cdot 5(19)$ & $9(22)$ & $9 \cdot 5(30)$ & $14(40)$ \\
& $5-82$ & $4-104$ & $3-373$ & $4-181$ \\
CD4 count & $16(75)$ & $21(27)$ & $16(72)$ & $20(61)$ \\
& $5-300$ & $5-64$ & $1-867$ & $2-450$ \\
\hline
\end{tabular}

Figures represent the median with means bracketed and the range.

ALT = alanine transaminase $U / 1$ (NR < 40); AST = asparate transaminase $U / 1(N R<40)$; Alk $P$ $=$ alkaline phosphatase U/l (30-130); Bilirubin = total bilirubin $\mu \mathrm{mol} / 1(\mathrm{NR}<17)$; CD4 count $=$ median $\mathrm{T}$ helper cell count $\left(\mathrm{NR}>500 \times 10^{6} / 1\right)$.

\section{Discussion}

This series represents the largest reported of ARSC. It also appears to be the first time that the association of pancreatic abnormalities with ARSC has been described.

In keeping with previous series, ${ }^{1}$ the most common form of ARSC was type III-papillary stenosis in association with sclerosing cholangitis. In an earlier series the presence of intraluminal polypoidal filling defects was noted $^{12}$ and we noted these in almost a third of cases, particularly in association with type III ARSC. Since the polyps are seen with diffuse, severe biliary inflammation their aetiology may be similar to pseudopolyps found in ulcerative colitis.

Opportunistic infections that most commonly cause ARSC include CMV, Cryptosporidium sp, ${ }^{3}$ and less commonly Mycobacterium avium intracellulare ${ }^{10}$ and Microsporidium..$^{13}$ In addition to these organisms, pancreatic disease in HIV infected patients may also be caused by Cryptococcus neoformans, Pneumocystis carinii, Toxoplasma gondii, and Mycobacterium tuberculosis. CMV and Cryptosporidium are responsible for $45 \%$ of infective causes of pancreatitis. ${ }^{5}$ As many patients with ARSC have intestinal infection with cytomegalovirus or Cryptosporidium at the time of diagnosis, ${ }^{14}$ it can be postulated that ARSC is a result of either ascending biliary infection for the protozoal infections, or systemic bloodborne infection for $\mathrm{CMV}$ and other opportunistic infections. This may explain the common association between ARSC and pancreatic abnormalities, with the organisms able to colonise both the pancreas and biliary tree. In the same way that infection causes stenosis of the biliary sphincter, we postulate that a similar process affects the pancreatic sphincter causing the ductal dilatation. The pancreatic abnormalities that we have detected may give rise to some of the abdominal pain that is a feature of ASRC and explain why biliary sphincterotomy is not always useful in relieving the pain. ${ }^{4}$

The results of our study support the important diagnostic role of ERCP in patients suspected of having ARSC and support the use of ampullary biopsy for microbiological diagnosis of infective causes. In addition the frequent finding of pancreatic abnormalities suggests an additional mechanism for the pain of the condition.

1 Cello JP. Acquired immunodeficiency syndrome cholangiopathy: spectrum of disease. Am f Med 1989;86: 539-46.

2 Dowsett JF, Miller R, Davidson R. Sclerosing cholangitis in acquired immunodeficiency syndrome. Scand $\mathcal{f}$ Gastroenterol 1988;23:1267-74

3 Benhamou Y, Caumes E, Gerosa Y, Cadranel JF, Dohin E, Katlama C, et al. AIDS-related cholangiopathy: critical analysis of a prospective series of 26 patients. Dig Dis $\mathrm{Sci}$ 1993;38:1113-8.

4 Ducreux M, Buffet C, Lamy P, Beaugerie L, Fritsch J, Choury A, et al. Diagnosis and prognosis of AIDS-related cholangitis. AIDS 1995;9:875-80.

5 Cappell MS, Hassan T. Pancreatic disease in AIDS-a review. $\mathcal{f}$ Clin Gastroenterol 1993;17:254-63.

6 Niedt GW, Schinella RA. Acquired immunodeficiency syndrome: clinicopathologic study of 56 autopsies. Arch Pathol Lab Med 1985;109:727-34.

7 Bonacini M. Pancreatic involvement in human immunodeficiency virus infection. $\mathcal{f}$ Clin Gastroenterol 1991;13: 58-64.

8 Wilcox CM, Forsmark CE, Grendell JH, Darragh TM, Cello JP. Cytomegalovirus-associated acute pancreatic disease in patients with the acquired immunodeficiency syndrome. Gastroenterology 1990;99:263-7.

9 Zazzo JF, Pichon F, Regnier B. HIV and the pancreas. Lancet 1987;2:1212-3.

10 Cello JP. Human immunodeficiency virus asscoiated biliary tract disease. Sem Liver Dis 1992;12:213-8.

11 Teare JP, Price R, Foster GR, McBride M, Main J. Reversible AIDS-related sclerosing cholangitis due to lymphoma. F Hepatol 1995;23:209-11.

12 Collins CD, Forbes A, Harcourt-Webster IN, Francis ND, Gleeson JA, Gazzard BG. Radiological and pathological features of AIDS-related polypoid cholangitis. Clin Radiol 1993;48:307-10.

13 Beaugerie L, Teilhac MF, Deluol AM, Fritsch J, Girard PM, Rosenbaum, et al. Cholangiopathy associated with Microsporidia infection of the common bile duct mucosa in a patient with HIV infection. Ann Intern Med 1992; in a patient

14 Forbes A, Blanshard C, Gazzard B. Natural history of AIDS related sclerosing cholangitis: a study of 20 cases. Gut 1993;34:116-21. 